\title{
Endoscopic resection of a large adenocarcinoma involving the appendix using a full-thickness resection device
}

The endoscopic treatment of adenomas involving the appendiceal orifice with endoscopic mucosal resection (EMR) or endoscopic submucosal dissection (ESD) is a big challenge, even for experienced endoscopists, because of the high risks of incomplete resection and perforation [1 - 3]. To date, these lesions have usually required surgical therapy, for example ileocecal resection. Endoscopic fullthickness resection (EFTR) using a fullthickness resection device (FTRD; Ovesco, Tübingen, Germany) was introduced in 2011. Since 2014, the device has had a Conformité Européene (CE) mark and been commercially available in Europe. The device has been well investigated in several studies $[4,5]$ and one indication for its use is lesions involving the appen$\operatorname{dix}[4,5]$.

We present the case of a large laterally spreading tumor (LST) invading the appendectomy site ( $\triangleright$ Fig. 1). A staging computed tomography (CT) scan of the chest, abdomen, and pelvis did not reveal any distant metastases or other masses. The resection procedure was performed with the patient under deep sedation (continuous propofol infusion) without endotracheal intubation. The patient received prophylactic antibiotic therapy with intravenous ciprofloxacin and metronidazole.

The lateral margins of the lesion were marked with argon plasma coagulation (25 W; Erbe APC 300) ( Fig.2a). To facilitate the introduction of the FTRD, a stiff guidewire was left in the cecum (Jagwire Guidewire ST Stiff; Boston Scientific) ( $>$ Fig. 2 b). The over-the-scope clip (OTSC) device was mounted on the tip of the colonoscope (EC 760 R; Fujifilm). The target lesion was grasped and pulled into the cap using grasping forceps ( $\boldsymbol{F}$ Fig. 2 c) and EFTR was performed ( $\mathbf{F i g . 2 d}$; - Video 1).

After the procedure, the patient developed acute appendicitis 12 hours later, which was treated conservatively with
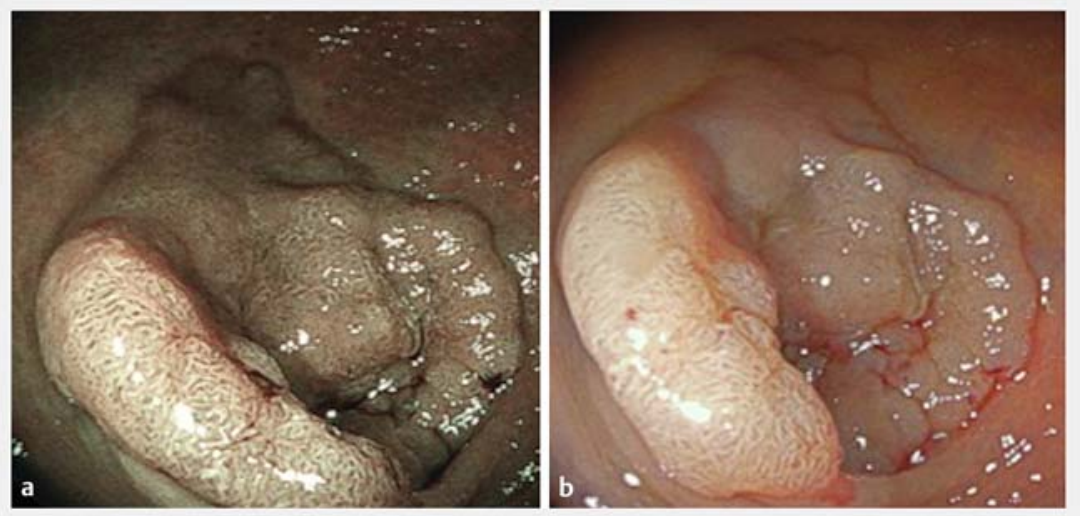

- Fig. 1 A large laterally spreading tumor invading the appendix is seen on: a blue laser imaging (BLI); b linked color imaging (LCI).
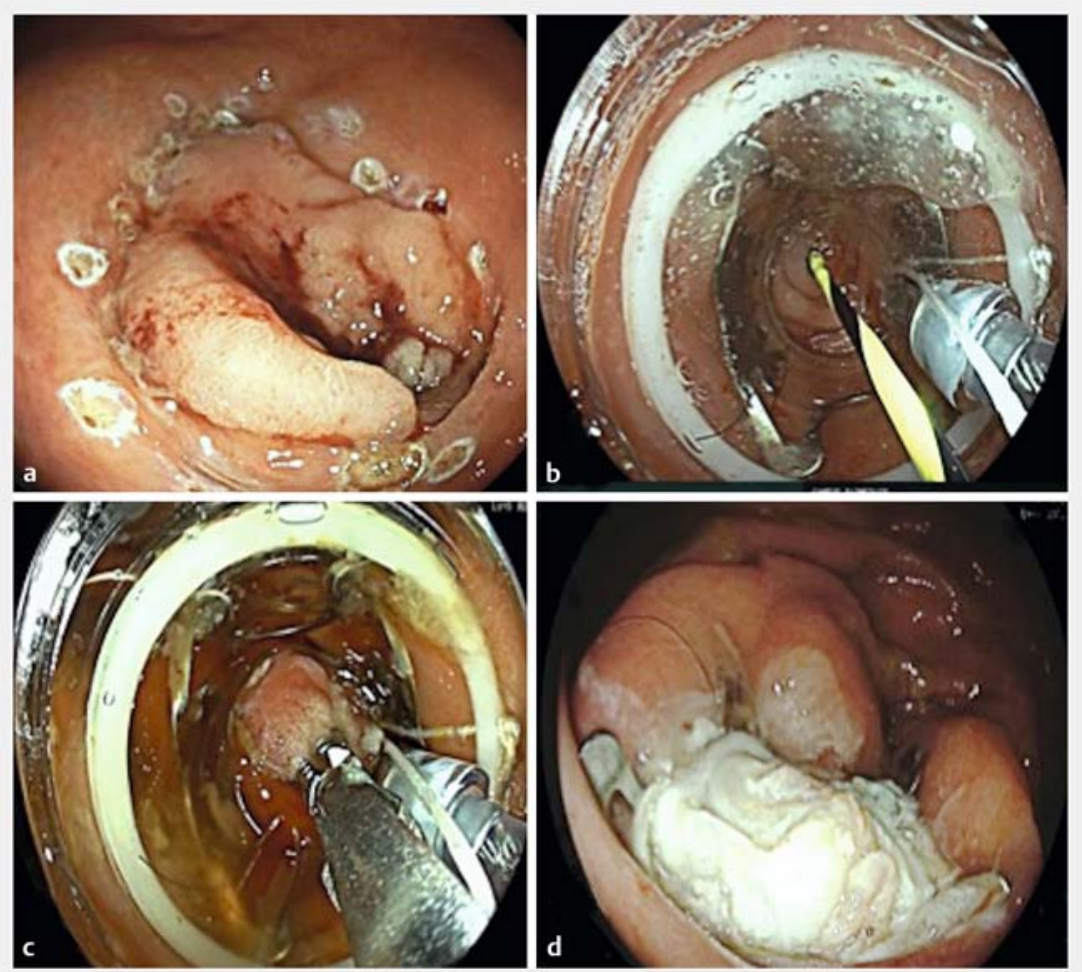

Fig. 2 Endoscopic views of the endoscopic full-thickness resection procedure: a the lesion is marked with argon plasma coagulation; $\mathbf{b}$ the full-thickness resection device is introduced; $\mathbf{c}$ the target lesion is grasped and pulled into the cap using grasping forceps; $\mathbf{d}$ the resection site seen after completion of the procedure. 

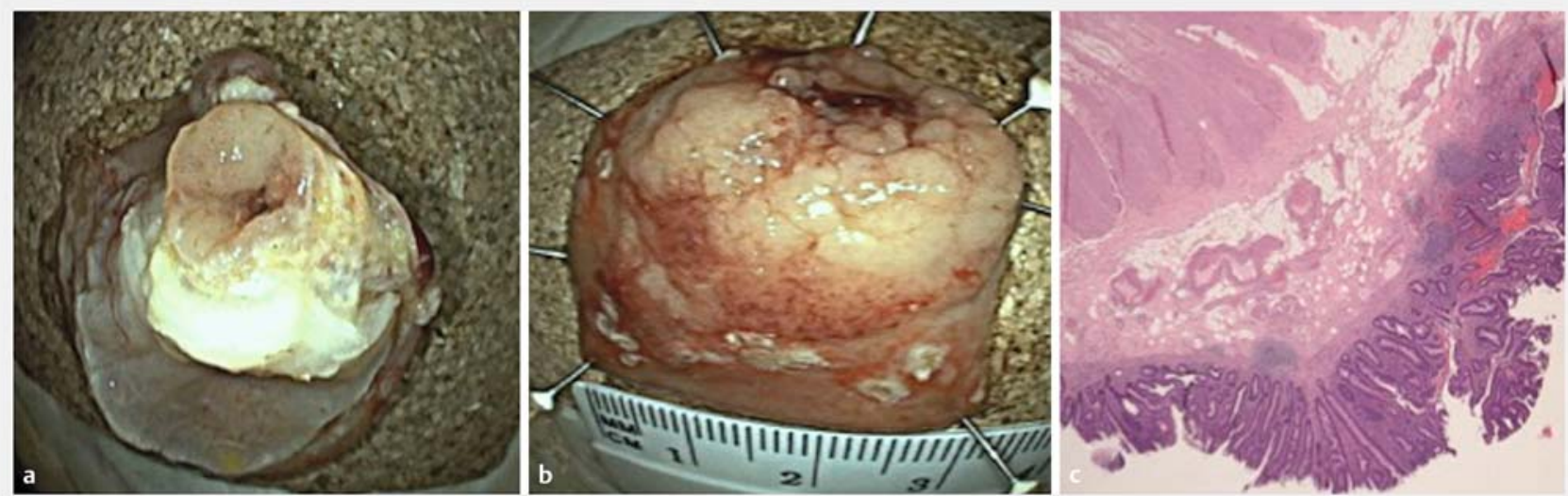

- Fig.3 Pathologic views of the specimen removed by endoscopic full-thickness resection showing: $\mathbf{a}$ a full-wall resection specimen; $\mathbf{b}$ the specimen after its placement onto a cork board; $\mathrm{c}$ the histopathologic appearance.

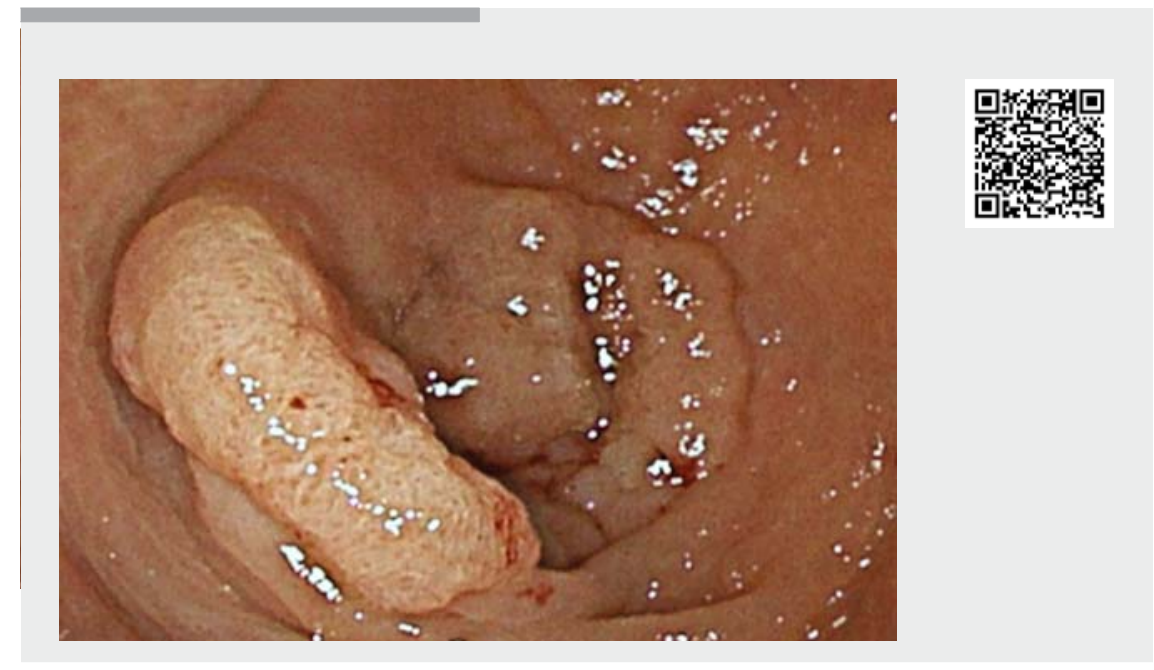

$\nabla$ Video 1 A full-thickness resection of a large laterally spreading tumor involving the appendix is performed using a full-thickness resection device.

medical therapy. Histology subsequently revealed a carcinoma in situ ( $>$ Fig. $\mathbf{3}$ ).

The risk of acute appendicitis after the closure of the appendiceal orifice with the FTRD is real and conservative treatment is certainly the best therapeutic choice. We are firmly convinced of the importance of the discussion with the patient prior to this procedure and of multidisciplinary management.

Endoscopy_UCTN_Code_TTT_1AQ_2AD

Competing interests
The authors

\section{Gianluca Andrisani, Francesco Di Matteo}

Digestive Endoscopy Unit, Campus Bio-Medico, Rome, Italy

\section{Corresponding author}

\section{Gianluca Andrisani, MD, PhD}

Digestive Endoscopy Unit, Campus Bio-

Medico, University of Rome, via Alvaro del Portillo 200, 00128 Roma, Italy gianluca.andrisani@gmail.com

\section{References}

[1] Jacob H, Toyonaga T, Ohara Y et al. Endoscopic submucosal dissection of cecal lesions in proximity to the appendiceal orifice. Endoscopy 2016; 48: 829-836

[2] Tate DJ, Desomer L, Awadie H et al. EMR of laterally spreading lesions around or involving the appendiceal orifice: technique, risk factors for failure, and outcomes of a tertiary referral cohort (with video). Gastrointest Endosc 2018; 87: 1279-1288.e2

[3] Song EM, Yang H], Lee H] et al. Endoscopic resection of cecal polyps involving the appendiceal orifice: A KASID multicenter study. Dig Dis Sci 2017; 62: $3138-3148$

[4] Schmidt A, Beyna T, Schumacher B et al. Colonoscopic full-thickness resection using an over-the-scope device: a prospective multicentre study in various indications. Gut 2018; 67: 1280 - 1289

[5] Bronzwaer MES, Bastiaansen BAJ, Koens L et al. Endoscopic full-thickness resection of polyps involving the appendiceal orifice: a prospective observational case study. Endosc Int Open 2018; 6: E1112-E1119

\section{Bibliography}

DOI https://doi.org/10.1055/a-0919-4249

Published online: 1.7.2019

Endoscopy 2019; 51: 1181-1182

(c) Georg Thieme Verlag KG

Stuttgart · New York

ISSN 0013-726X 